\title{
Bamboo - the eco-friendly material - one of the material solutions of the sustainable interior design in Viet Nam
}

\author{
Thi Bich Vân Nguyen ${ }^{1, *}$ \\ ${ }^{1}$ University of Architecture Ho Chi Minh City, 196 Pasteur str., Ward 6, District 3, Ho Chi Minh City, \\ Vietnam
}

\begin{abstract}
Today, sustainable architecture is not just a trend but an architectural style that has become a "revolution." The lack of interior focus in the process of sustainable architectural development has created a gap between architects, interior designers, clients, or those wishing to live in a responsible construction environment. Responsibility for nature and people. Although environmentally sustainable interior design (ESID) has become a major issue in interior design practice, the frequency with which interior designers make sustainable choices in real practice is still limited, especially when choosing materials. Among these materials, this study wants to emphasize bamboo materials in sustainable furniture design in Vietnam. Indeed, this is a common material in sustainable design in Vietnam, and there are also many studies on the use of bamboo materials in housing construction. However, the paper raises main issues: role of bamboo material in interior design in Vietnam, the better access to a basic knowledge of sustainability, and more up-to-date information about sustainable materials will play a critical role in promoting sustainable practicing in Viet Nam.
\end{abstract}

\section{Introduction}

In the world, the concept of "green architecture" has never been talked about so much as it is now. "Green architecture" or "sustainable architecture" is used to refer to the construction of buildings and the use of environmentally friendly and effective methods. It is noteworthy that sustainable interior design always considers key factors, such as material selection and energy use to ensure a micro-climate of the environment. The danger from the devastation of the environment is becoming more and more seriously, greatly affecting the life of every species on earth. Sustainable, environmentally friendly use of materials is an important goal of many interior design and construction companies. Among the sustainable building materials that researchers have focused on, bamboo is known to be the most distinctive material in its role in architectural and interior design.

Because of its high growth rate and easy processing, bamboo is a promising renewable resource that could potentially replace slow growing hardwood. Bamboo's good mechanical

\footnotetext{
*Corresponding author: bichvandesigner@gmail.com
} 
properties, low costs, abundant availability in developing countries, and potential use in a multitude of applications show the potential of this versatile resource for income generation through commercialization of the resource. Moreover, because of its rapid growth and extensive root network, Bamboo as a plant is a good carbon fixator, erosion controller, and water table preserver. From ancient times, the image of bamboo is very familiar to the people of Vietnam. Bamboo appears in the village, passing with the people through many ups and downs in the life. Few people think that today the gentle bamboo dust is very durable and strong to be used in the field of architecture, construction, and especially in the field of furniture. [2]

The bamboo plant is an eminent means to start up reforestation, as the plant often has a positive effect on groundwater level and soil improvement through the nutrients in the plant debris. Recently, bamboo has been hailed as a super-new material, which can be used for a variety of purposes from textiles to construction. Bamboo also has the ability to absorb large amounts of carbon dioxide, the largest greenhouse gas, and help many poor people make money. The role of bamboo is changing. Many people even call bamboo "wood of the $21 \mathrm{st}$ century". Today, in Viet Nam, bamboo is used in a wide range of household items, becoming part of the load-bearing structure of home designs. This article would like to emphasize the applications of bamboo materials to interior components, such as ceilings, walls, floors. With superior features, bamboo deserves to be the material that needs to be incorporated into the interior design and outline future directions for sustainable development in Viet Nam.

\section{Literature review}

Environmental sustainability is becoming a major concern within the interior design field due to the extensive resources needed for interior use (Ruff \& Olson, 2009). Sustainable interior design practices are actions that lessen environmental impact due to the site selection, water use, energy use, and material selection. With these considerations, interior designers are able to provide a physiologically and psychologically healthy indoor environment (Kang \& Guerin, 2009) [3]. Overall, environmentally sustainable interior design minimizes negative effects and maximizes positive effects on environmental systems over the life cycle of a building (Kang \& Guerin, 2008) by blending solutions of the past with new technology of today (Loftness, 2007) [4].

Research on bamboo in Vietnam has been around for a long time. It can be said that the first study of bamboo in Vietnam belonged to a Frenchman in the Oriental Medicine (Lecomte 1923). In the 1960s, Pham Quang Do studied bamboo cultivation and harvesting techniques in Viet Nam (Pham Quang Do, 1963). In the same time, research on planting, propagation, care, processing and preservation techniques was carried out. For example: classification of bamboos in morphology (Tran DInh Dai 1967). As of 2007, more than 100 bamboo publications were distributed throughout the country. However, the research on bamboo is quite sporadic, scattered throughout the country, the results of the study fall into many categories: articles, books or reports when the topic ends. Research in the application of bamboo in the design of buildings and furniture in Vietnam only exists in the newspaper ads. There are no studies that emphasize the role of bamboo in sustainable design and the incentives for designers, contractors, and investors to develop bamboo applications for ecodesign, environmental sustainability.

Research on existing bamboo applications Environmental sustainability is becoming a major concern in the field of interior design due to the resources needed for interior use (Ruff \& Olson, 2009). Sustainable interior design practices are actions that reduce the environmental impact of location selection, water use, energy use, and material selection. With these considerations, interior designers can provide a physiologically sound physiological and psychological environment (Kang \& Guerin, 2009). In general, 
environmentally sustainable interior design minimizes negative impacts and maximizes positive impacts on environmental systems throughout the life cycle of a building (Kang \& Guerin, 2008). By combining past solutions with today's new technology (Loftness, 2007) [4]. This paper presents issues related to bamboo and its applications to interior design. This will be the basis for research on the potential and direction of sustainable development in interior design using bamboo materials. This is also the long-term direction that the author wants to address in later studies.

\section{Materials and methods}

This study is designed in seven steps

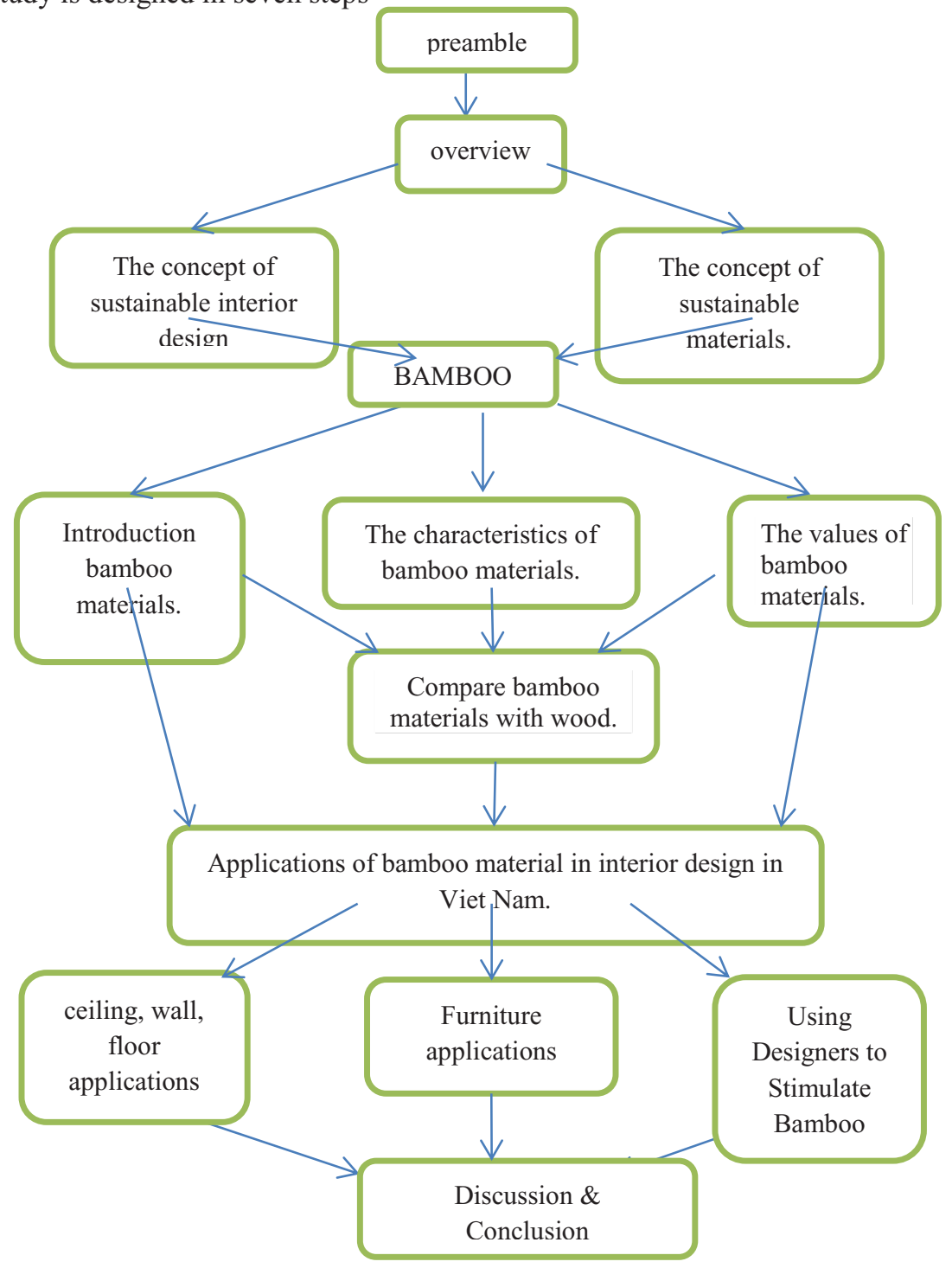

Fig. 1. Research diagram. 
Step1. The concept of sustainable interior design and sustainable materials.

Step 2. Introduction bamboo materials.

Step 3. Characteristics and values of bamboo materials.

Step 4. Compare bamboo materials with wood.

Step 5. Applications of bamboo in interior design in Viet Nam.

Research Methodology: Methods of fieldwork; Historical Method; Methods of sociological surveys; Statistical Methods; Analytical Methods; Integrated Method; Comparative method; Multi-criteria assessment Method.

\section{Results}

\subsection{Step 1. The concept of sustainable interior design and sustainable materials}

\subsubsection{Environmentally sustainable interior design (ESID)}

Environment interior design and sustainability are some of the more popular buzzwords that have been bandied around over the past few years. As interior projects specialists are recognized that whilst sustainability is important, it needs to be melded into a healthy and productive working environment. Sustainable interior design creates interior spaces using design principles, such as functionality, accessibility, and aesthetics and expands the focus to include environmental considerations. For example, sustainable design projects are influenced by such factors as planning efficient use of space, choosing materials with low environmental impacts, and reducing energy consumption, pollution, and waste. Sustainable interior designers are committed to finding ways to balance aesthetics and functionality with choices that reduce the environmental impact of their designs [6]. (http://www.eco.ca/careerprofiles/sustainable-interior-designer/)

\subsubsection{Sustainable materials}

Sustainable products are becoming the accepted norm in the world today and attract more interest than before. A sustainable product is one which protects the environment during its entire life. That is, from the moment the raw materials are extracted from the source to the time the final product is disposed of, there must be no permanent damage caused to the environment. A sustainable material or a sustainable resource is something whose production is supported indefinitely by nature, which means that the resource is used up at the same speed that it is renewed. Bamboo and wood are the sustainable resources when the trees are harvested at the same rate as new trees are planted. The key is to use this resource wisely selecting bamboo and wood from responsibly managed forests, substituting engineered wood and alternative materials where appropriate, reusing salvaged wood, and minimizing waste, so the process is slowed down and gives the trees time to mature.

Sustainable materials are something that you hear more and more when it comes to buildings, your own home and even smaller structures. As we are responsible for our planet, we need to look after it and use non-renewable fuel and materials. We cause much more harm than was previously thought. Nowadays, we are more inclined to opt for the sustainable route rather than one that will pump tons of $\mathrm{CO} 2$ into the atmosphere or use materials that are detrimental to the environment. 


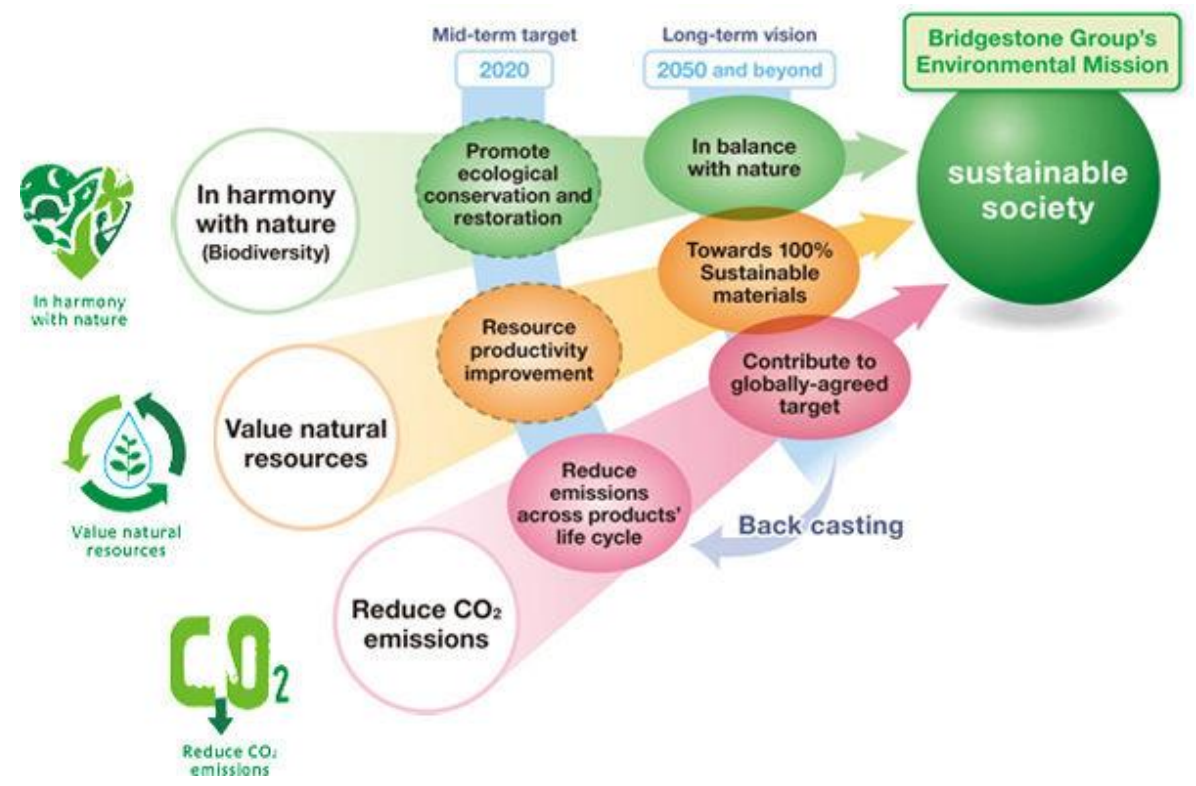

Fig. 2. Long-term Environmental Vision and Use of "100\% Sustainable Materials" [7].

Constructing with sustainable materials is not only good for the planet and common sense, it can save the client money, help preserve our heritage, respond to planning policies and help get credits in BREEAM, LEED and others environmental assessment tools. Sustainable manufacturing is an essential aspect of widening efforts to create an ecologically responsible world. It requires a lot of research, local sourcing, waste control and a fair bit of open mindedness. The effort is worth it though and is a promise of a better future for those who will follow in our footsteps. In Viet Nam, The Green Council of Vietnam has also announced LOTUS for Interior Spaces is a system guiding the design and assessing the sustainability performance of interior fit- out projects. This also shows the interest of organizations in green design and sustainable interior design.

The Sustainability of Bamboo.

From ancient times, the image of bamboo is very familiar to the people of Vietnam. Bamboo appears in the village, the same people through many ups and downs. Few people think that today from the gentle bamboo dust is so durable, so strong in the field of architecture - construction. Because of its widespread availability in developing countries, bamboo offers many opportunities for sustainable development, especially in developing countries, including VietNam, where this development is needed most. Furthermore, bamboo can easily be processed manually or industrially, and has a low cost due to its abundant availability.

Bamboo needs to be treated well before being put to use to limit insect infestation and increase bamboo life. The common practice among people in the past was to soak in mud ponds for 3-6 months. In addition, bamboo has a waterproof layer, so the paint has many obstacles, but this has been overcome thanks to some special paint. Owing to its superior properties, bamboo is a good solution to heat up the building, while ensuring aesthetics and increasing the value of the building due to the local character of the material [8].

\subsection{Step 2. Introduction to bamboo material}

\subsubsection{Introduction to bamboo material}


Bamboo material is a traditional material that is particularly good for construction in Vietnam as bamboo is a rich source of material and can be used in just five years. The ancient bamboo family is attached to Vietnamese architecture, from the downstream domain to the lowland. For farmers, bamboo is as a house and a production tool. If the enemies come, bamboo is used to build ramparts, to fight, and destroy the enemies. Today, when we go to rural Vietnam, we still see some houses made of rough materials such as clay mixed with straw, bamboo leaves. Bamboo is associated with the history and culture of the nation, bamboo goes along with the childhood of every Vietnamese person in the countryside, and when thinking of the applications of bamboo, we immediately think of fine arts and crafts. Beautiful visuals or tables and chairs, rustic bamboo houses. The species number of this group is very large, and is considered to be the largest in the Ministry. Bamboo is also a flowering plant, but only blooms once at the end of life. Usually bamboo has a blooming time of about 5 - 60 years [8]. Bamboo is attached to the life of most Vietnamese peasants through the image of ancient bamboo villages that are associated with memories of many generations. For people in the old days, it is hard to forget a rest in the bamboo hammock in the noon.

\subsubsection{Benefits of Bamboo}

There are a lot of benefits of bamboo. First of all, it is a natural anti-bacterial that will help to the children or people who cannot be in contact with bacteria because of the fear of sickness. Another great feature of bamboo is that it is water resistant, which makes it a better choice than many other hardwood floors that can stain or deteriorate when any kind of moisture gets in contact. It is also an extremely durable piece of material that is easy to move, yet still hard enough to provide you with great flooring.

Luckily, the harvesting of bamboo is also sustainable for the earth. The bamboo tree (or grass) is grown in abundance in many parts of the world. In some cases, it is even problematic for landowners because they are unable to access all of their land. In any case, the bamboo is a material that is perfect for sustainable construction. They can offer great quality hardwood floors, but they do not cost a lot to the environment at all.

The bamboo is also a great anti-bacterial and it is also water resistant. Both of these features make it a superior product to many of the other hardwoods that are used today. Many of the rare trees that are used for wood flooring are unable to regenerate in the way that bamboo has. If you want to change the world and provide yourself with a sustainable home, then bamboo flooring is one great way to go.

\subsection{Step 3. Characteristics and values of bamboo materials}

\subsubsection{Characteristics of bamboo material}

Bamboo is one of the most important nature's substitute for the endangered rainforest hardwoods. It is a quick-growing, versatile, non-timber forest product whose rate of biomass generation is unsurpassed by any other plants. With a 10-30\% annual increase in biomass versus $2-5 \%$ for trees, bamboo creates greater yields of raw material for use. It is utilized extensively for a wide range of purposes. The strength of the culms, their straightness, smoothness, lightness combined with hardness and greater hollowness; the facility and regularity with which they can be split; the different sizes, various lengths and thickness of their joints make them suitable for numerous end products/purposes. The versatility of bamboo outmatches most tree species. It is known to be a natural and excellent raw material for manufacturing strong and sturdy furniture, handicrafts, and novelty items [8]. 
Bamboo is extremely strong whilst remaining flexible meaning it is often used as a building material and in the making of furniture. As it doesn't soak up water, it is an ideal fibre for bathroom wares. Bamboo is also one of the fastest growing plants in the world with bamboo stems emerging from the ground in reaching their full height in a single growing season of around three to four months. This makes bamboo highly sustainable as once it has been cut down it grows back readily. In recent years, bamboo has also been used in the manufacture of textiles with cloth, yarn and clothing made of bamboo fibres.

Some of the characteristics of bamboo are listed below:

- an effective erosion control plant and natural control barrier due to its widespread root system and large canopy;

- reduces runoff, prevents massive soil erosion;

- keeps twice so much water in the watershed;

- sustains riverbanks;

- protects surrounding environment during typhoons due to its height;

- regenerates and resilient even after strong typhoons;

- helps mitigate water pollution due to its high nitrogen consumption;

- minimizes $\mathrm{CO} 2$ gases (sequesters up to 12 tons of $\mathrm{CO} 2$ from the air per hectare); and

- generates up to $35 \%$ more oxygen then equivalent stand of trees.

Bamboo is an important component of development wherein all types of people have adequate access to. It requires little attention during its growing/production cycle and can occupy the same ecological niche as that of trees. It is well suited for agroforestry and healthy ecosystems. It requires only a modest capital investment to generate a steady income. Around the globe, a lot of individuals and communities are dependent on bamboo for their subsistence, shelter, and every-day utilities. [10]

\subsubsection{Values of Bamboo Material}

A. Economic value:

- Bamboo grows fast

Bamboo grows very fast, not only bamboo is easy to adapt to all living environments such as arid, rocky, ponds. As a result, the world's bamboo forest area reaches 37 million hectares, bringing high economic benefits. Bamboo planted for about 5 years gave good quality while, to be so hard to harvest natural wood have to wait 50 years or more.

- Many applications in life

All parts of bamboo are economically beneficial to humans. Bamboo stems with stiffness and toughness have long been used as working tools for farmers, such as shovels and shovels, household items such as chopsticks and baskets, to Beds, cabinets, bamboo mills, etc., such as the construction of the door. Today, bamboo is used as fine arts and crafts, or become civilized building materials such as wall tiles, floor tiles.

- Land protection

Bamboo has a spreading root on the ground, which has a strong hold on the soil. Tre also has the effect of water retention, protection of sloping land, erosion control, landslide. Planting bamboo forest in a wide area, especially the two sides of the river, has the effect of protecting the dyke very well, reducing the impact of flood, dyke breaking, ensuring ecological balance. In addition, the more leaves fall in the bamboo forest, the increased air humidity is very beneficial for soil fertility. There is a source of food of rare animals, such as bears, elephants.

B. Social values:

Bamboo beautifies the landscape, enriching the culture. Many bamboo stilts rise beside the fountains, gracious and attractive ethnic people, making people feel new. Traveling, 
organizing visits to bamboo areas also attracts visitors. In addition, exploitation and application of bamboo handicrafts also solves a large number of redundant workers in rural and mountainous areas, helping to alleviate poverty. Today, despite the modern technology, there are countless numbers. New materials, but bamboo materials are appreciated and honored with distinctive beauty. From the inherent properties of bamboo, with modern technology, bamboo material has become one of the building materials not only of quality but also environmentally friendly. That is why bamboo is known as GREEN STEEL and becomes a perfect substitute for wood in the future, as the source of wood is exhausted. Instead of cutting a 50 year-old timbers, why not choose bamboo for the sustainability of your floor and the sustainability of the environment.

As more and more bamboo products become available, consumers looking for environmentally-friendly alternatives to hardwood floors, furniture, cabinets, wall coverings, ceilings, and more are finding that bamboo is not only a 'green' alternative but often superior to traditional hardwoods. Bamboo is light but very durable and more resistant to wear and dings than oak, maple, and most other hardwoods. What's more, bamboo is naturally resistant to moisture which makes it far less likely to stain, cup, or warp from spills or fluctuations in humidity. Available in a wide variety of finishes, bamboo is rapidly becoming a favorite of interior designers and discriminating homeowners everywhere. It is very easy to clean and maintain and offers the natural beauty and versatility of hardwoods without the environmental impact.

\subsection{Step 4. Compare bamboo materials with wood}

\subsubsection{Bamboo is as an Alternative for Hardwood}

In the previous subsection, it was found that an increasing use of renewable raw materials may be necessary to bring down the Ecological Footprint to a sustainable level. However, we also found that at the moment, due to increasing consumption and population numbers, raw material demand is set to increase while supply diminishes. This also applies for timber, as the increasing consumption figures and the decreasing forest areas, especially for tropical timber, show. Also, since emerging economies started to raise their consumption, the pressure on timber will continue to grow.

Due to the expected higher annual yields, and the ability of bamboo plantations to be established on areas of land where trees may not survive, bamboo may be a promising alternative to help meet the increasing demand in raw materials and timber in particular. Thus bamboo may play an important role at the supply side of the Ecological Footprint, to meet future human needs for fibers and timber used as input for housing, clothing, interior finishing, furniture, household products and other consumer durables. Bamboo grows faster than softwood, but has hardwood properties. Since industrial bamboo materials are still priced more or less at the same level as hardwood materials (which is higher than most softwoods), the best bet for bamboo is to initially target the markets in which hardwood is used. Bamboo materials are already familiar to the Vietnamese people. In addition to the use in the structure, interior, exterior, bamboo is also a material solution effective in preventing heat for the building [11]. With its toughness, bright colors, bamboo can be used in both structural and decorative applications. In addition, bamboo materials are not as radiant as concrete, reducing the temperature significantly, especially in accordance with Vietnam's hot and humid climate.

\subsubsection{Compare bamboo materials with wood}


As a grass, bamboo does not have sapwood, heartwood, or growth rings. Its texture is uniform and will range from medium to fine depending on density. The color is generally pale yellow to almost white. Bamboo differs from wood as it has a hollow stem and lacks rays or visible pores. In order to process bamboo as a timber, the bamboo fibers are pulled, soaked and then pressed together with adhesives. However, as most bamboo is processed in its original country, the standards may vary. Hence, some manufactures may use cheap adhesives to process the bamboo, which may emit into the air and harm the owners. It is advisable to check the formaldehyde content of the material before acquiring. It is also slightly difficult to work with bamboo, as it tends to split and pull out when being cross-cut. Furthermore, bamboo is very high in silica which may lead to dulling of blades and processing tools [11].

\section{BAMBOO CONSERVATION - THE \$EN\$ IBLE WAY}

WOOD

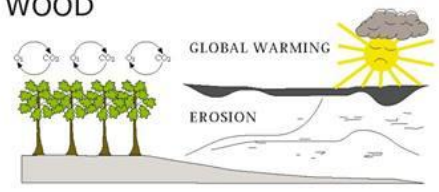

HARVEST ONCE EVERY TEN YEARS
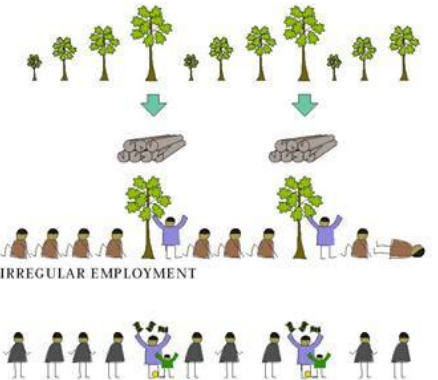

IRREGULAR INCOME

21

$\begin{array}{lllllllllllll}0 & 5 & 10 & 15 & 20 & 25 & \text { YEARS } & 0 & 5 & 10 & 15 & 20 & 25\end{array}$

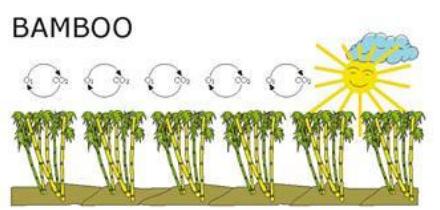

ANNUAL CROP

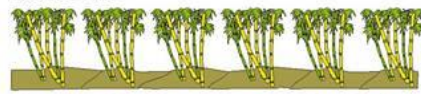

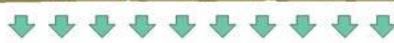
13013
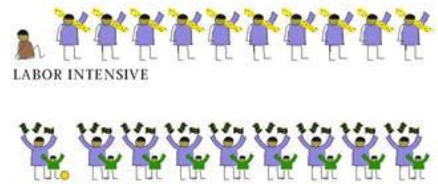

REGULAR INCOME

$\begin{array}{llllll}0 & 5 & 10 & 15 & 20 & 25\end{array}$

Fig. 3. Bamboo regenerates annually, bringing economic benefits [15].

In addition to the use in force-bearing structures, bamboo is also used as a partition inside and outside the house. These walls are usually very light, have good air circulation, do not radiate heat, reduce room temperature. However, walls made of bamboo do not have good soundproofing effect.

\subsection{Step 5. Application of bamboo in interior design}

\subsubsection{Bamboo flooring is an ecological product}

Bamboo is a grassy plant, so the growth rate and development of bamboo is very fast. Only about 5 years have given a good quality bamboo lace into production for building materials. Not only does bamboo have the ability to regenerate itself, when mature bamboo litters are harvested, young shoots are sprouting up to prepare for a new cycle. Therefore, bamboo forest, if properly exploited, will always retain the green color to bring high economic efficiency. Bamboo flooring in the future will become a sustainable material, a perfect substitute for natural wood and contributes to protecting the environment and keeping the 
earth green [12]. The color of bamboo flooring is a natural color that does not use industrial paints to paint toxic to the environment and to the health of the consumer.

- Suitable for any interior design

Bamboo flooring is easy to coordinate style with the design of construction and easy to combine with the furniture from classic to modern. Whether the style of your home is quiet, light or modern, fresh, bright natural color, warm or classic, as well as classic as the shell color, will meet all the aesthetic requirements of the landlord. Using bamboo flooring is now considered "stylish" and innovative. Many homeowners are proud of themselves on being a pioneer in Vietnam for the new trend of using natural, environmentally friendly, and unique materials, catching up with the trend of civilized materials from developed countries like Europe. Some people are proud of using bamboo flooring as contributing to environmental protection, fighting climate change, keeping the earth green. Others who use bamboo flooring boast a culture of love and tradition, when the bamboo is associated with Vietnamese history and culture. Whatever the reason, bamboo floor users are considered to be upstream, "cool" and have a high sense of social responsibility.

- Bamboo floor is good for health

Bamboo material does not produce heat or absorb heat so it is possible to create coolness in summer and warm in winter. Living with bamboo floor for long time will help to reduce the risk of diseases, such as arthritis, cardiovascular, etc. Bamboo floor also absorb the ultraviolet rays and solar radiation, along with elegant pattern should be beneficial. For vision, minimize myopia. Besides, the elastic bamboo flooring combined with 8 layers of UV and 2 layers of aluminum oxide will reduce the slipperiness for the user, especially good for elderly family and young children. Finally, using bamboo flooring will create living space close to nature, help to relax spirit, dispel all fatigue, tension [12].

- The price of bamboo floor is reasonable

Bamboo flooring is one of the natural flooring types, with natural beauty because of the random arrangement of unique and different bamboo eyes known for ordinary wood flooring. Many people think that bamboo flooring prices are high. However, the 5-year-old bamboo has given good quality to put into bamboo flooring, not only bamboo can reproduce quickly, so bamboo materials are abundant and available for production. The price of bamboo flooring is cheaper than the natural wood flooring on the market. Besides, bamboo flooring usually has a yin-yang style, so it is easy to repeat the bamboo flooring quickly during the day, saving time and money on installation [12].

Bamboo flooring with these advantages along with sustainability and environmental protection will definitely be a perfect flooring material for your family. Bamboo materials are already familiar to the Vietnamese people. In addition to the use in the structure, interior, exterior, bamboo is also a material solution effective in preventing heat for the building. According to Bamboo Habitat, bamboo houses have the same durability as bungalows. In Japan, there are bamboo houses over 200 years old. Not only malleable, bamboo is also very hard (27\% oak wood), and is called "green steel", with more mechanical properties suitable for construction than wood. In addition, bamboo materials are not as radiant as concrete, reducing the temperature significantly, especially in accordance with Vietnam's hot and humid climate. 


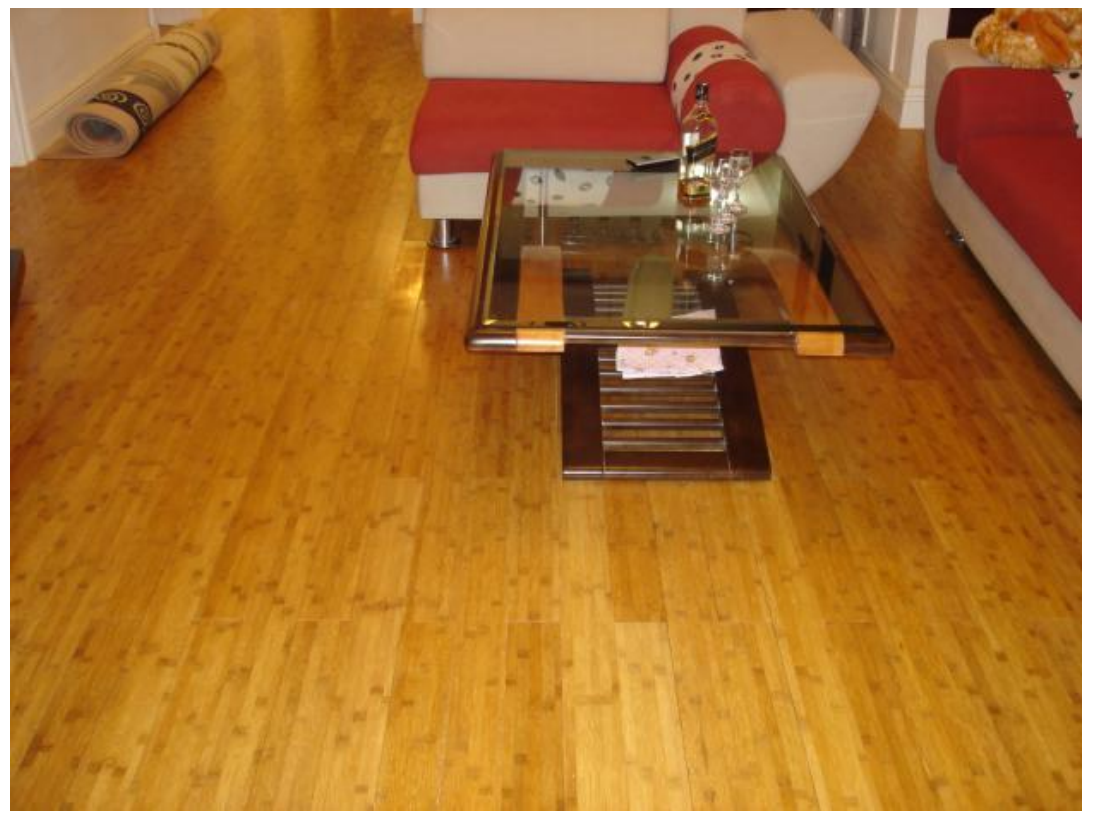

Fig. 4. Bamboo floor [16].

In addition to the application of flooring materials, bamboo is also applied to the wall and roof. With special texture, bamboo material has really created aesthetic value, impressive works.

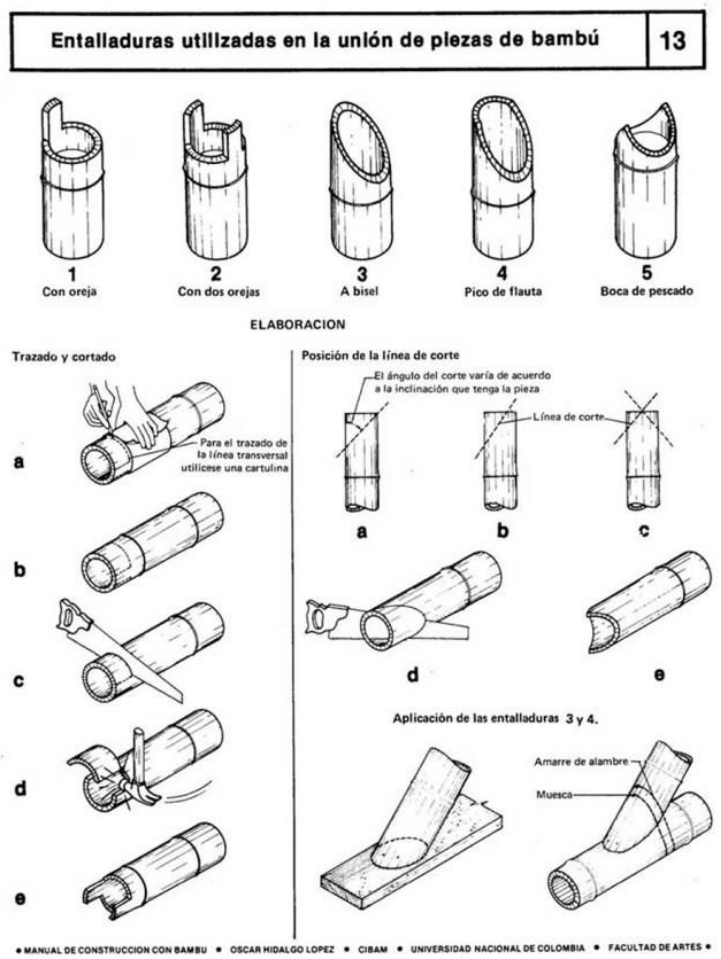

Fig. 5. Some ways to cut bamboo to make joints \& Some ways to connect bamboo [1]. 
Works using bamboo texture:

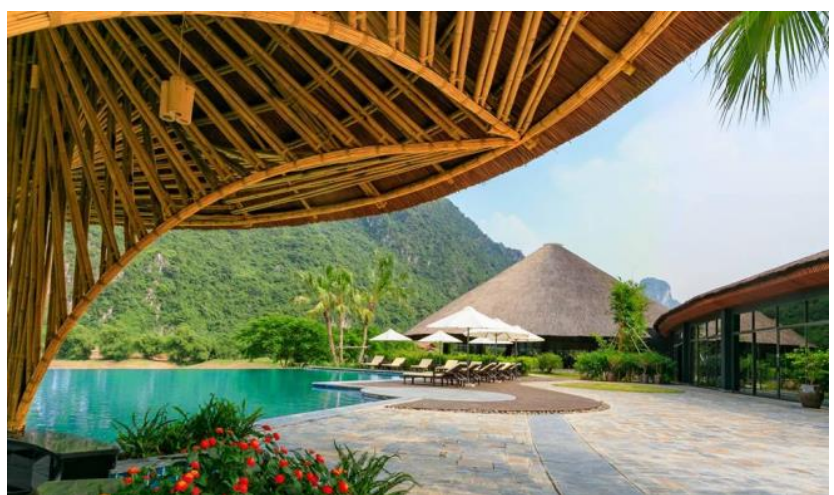

Fig. 6. Serena Hotspring Resort [15].

According to ThS.KTS.Tran Quoc Viet, deputy head of the Architecture and Planning Department at Hanoi University of Civil Engineering, "Bamboo is a fibrous, multi-layered material that is very good at reducing heat. The work, which is a traditional material, is used in many climates, but due to the particularity of the link it is more optimal to be processed and combined with other materials (straw, mud, soil, etc.). " .

Combining bamboo texture with leaf roof to create optimal thermal efficiency effect.

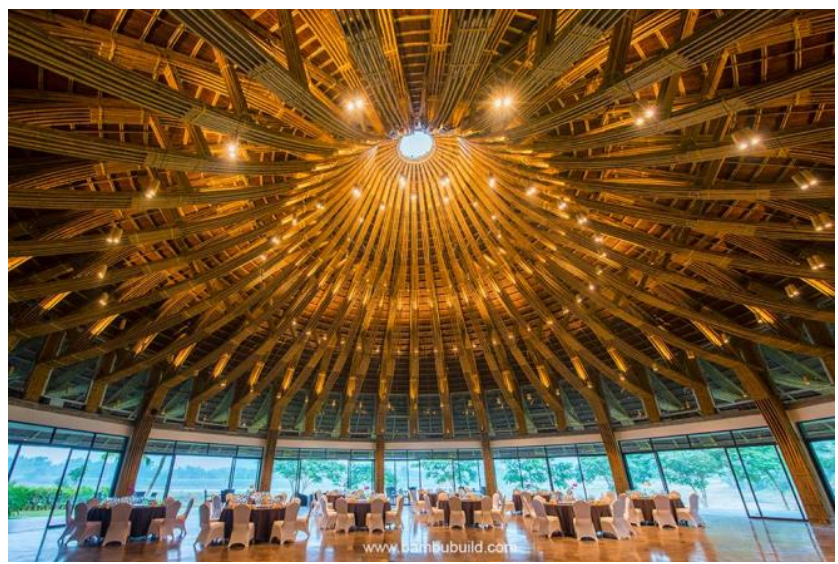

Fig. 7. The biggest bamboo conical dome in Vietnam has been completed in Serena Hotspring Resort [15].

With its compact nature, tubular, bamboo materials are used very flexibly. The bamboo trunks will be skillfully combined with joints to form bearing columns or decorate the building. Each locality works different, so the bamboo joints also need to be changed for the appropriate ones. From simple to complex, from strings to iron frames and bolts, from little to a lot of money, depending on the nature and level of investment of the used building. Once completed, it will give a lot of experience to change the technique of joints on new bamboo constructions.

\subsubsection{Furniture applications}

Bamboo home furniture comes in more varieties of styles and finishes than before. Furniture designers are using bamboo in innovative designs, either in all-bamboo or composite 
materials. Bamboo furniture can withstand everyday use. It is far more resistant to damage than traditional hardwoods. Bamboo is even used in cutting boards for this reason; it can take the beating of repeated knife use and still remain beautiful, and bamboo is gentler on knife blades than other woods. This comes in handy if you are plan on giving a bamboo chair a good deal of use.

Bamboo furniture is undergoing a revolution as of late. The rustic furniture of the sixties and seventies, made from unmilled bamboo shoots and poles, is still available. There is also a new face to this type of furniture as well. Milled, sanded, and finished bamboo furniture rivals any hardwood furniture in durability and beauty. Add to the fact bamboo is one of the world's most environmentally-friendly resources to raise, harvest and use, and it's clear why bamboo has become one of the hottest furniture building materials on the market.

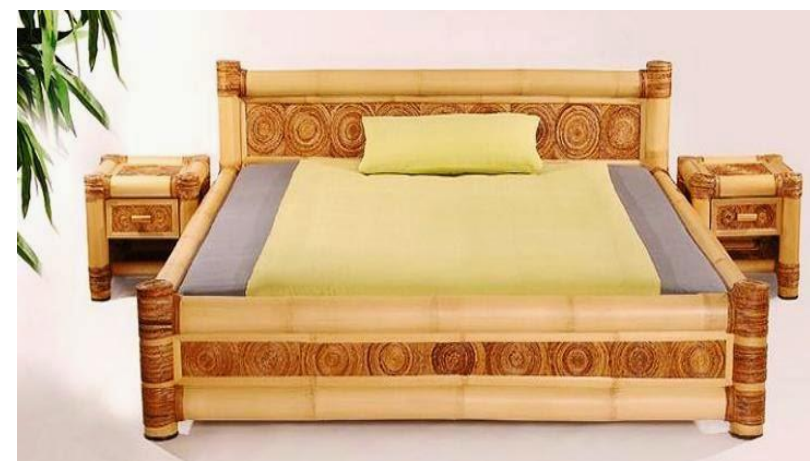

Fig. 8. The Bamboo bed [15].

The design is a mechanism to show an awareness of the importance of the needs and quality of life through creative and innovative ways. Revenue awareness now, a lot of furniture design in the market focused on the continuity between current needs and environmental concerns to ensure the life cycle assessment as a result of product benefit. Bamboo materials importance to environmental sustainability supported by success in applying design furniture designer to include design elements with environmental relationships to enhance the product in order to gain market attention [17].. Bamboo biocomposite proved by many researchers to have high benefits as an alternative material for the production of furniture and other components. A variety of new furniture designs have been produced using smart materials is based on the proven quality furniture compare to solid wood material. High innovation in bamboo fiber can improve the durability even bent and shaped materials such as solid wood other [11]. Research and development in making advanced bio-based furniture products around the world are able to produce continuous improvement in product innovation success. Initiatives to increase the use of bio-composite value highly praised and encouraged for these materials to reduce environmental impact, improve innovation and advanced technology in the manufacturing process.

Besides the rustic furniture, it's more likely that you've been drawn to bamboo furniture by the newer, more finished bamboo furniture hitting the market. If that's the case, here are a few basics about building fine furniture with bamboo so you're well-informed when you hit the show floor.

- Color: Furniture made from bamboo is available in two colors. The shade referred to as natural bamboo is akin to the light color of maple. That's the color of bamboo if it is manufactured into furniture without utilizing any techniques to alter its natural appearance. The other shade is carbonized bamboo. Carbonized bamboo is the result of a steaming process that brings out a darker, amber shade in the wood. 
- Composition: The smooth, fine furniture look you're drawn to is accomplished by cutting the bamboo stalk (bamboo is actually a grass, not a tree, hence a stalk, not a trunk) into small, narrow sections and then gluing those pieces of wood together. Depending on which face is used, the end result is bamboo plywood or vertical grain bamboo panels. Panels are a little bit sturdier, though visually there is little difference between the two.

Bamboo also has the characteristics of materials and textures are very useful for designers to create a unique design and original, it is imperative that users reacted positively [10]. Now, many examples related to bamboo furniture that can be used as an important consideration in choosing furniture bamboo [15]. There are several designs of amazing furniture use bamboo material simplicity, many furniture designers prove bamboo materials is not only resilient and pliable, but tremendously powerful internal and external. For example young designer Kenyon Yeh, a designer has produced designs stool named Jufuku from Japanese word means duplication or repetition. Stool Jufuku clearly emphasizes the best quality bamboo to produce designs without parts or fasteners, where each piece of bamboo on Jufuku Stool is made from a single structure shape which is then repeated to complete each form of the object but the result is still beautiful in a simple, minimalist and attractive. The famous designers Anthony Marschak discovered the magic of bamboo while looking for ideas as versatile materials other than solid wood for his design for Spring Chair. Spring Chair is produced from renewable resources has become a sustainable furniture and other luxury furniture comparable. Strength and flexibility of bamboo materials to create natural bending very important in the design and ergonomic nature [8].

\subsubsection{Using designers to stimulate bamboo}

At the Workshop on green building held on April 16, 2014, Vietnam Association of Architects said that in the traditional architecture of Vietnam, green elements are always linked closely between "people - ants architecture - nature" in a harmonious way, friendly. With the rapid urbanization of today, the development of green buildings and the use of energy efficiency becomes necessary to exploit the wisdom and traditional experience combined with technology, Modern materials fit the reality. For over 10 years, the team of designers, architects are always aware and devote a lot of passion for environmentally friendly materials, including bamboo materials. Among them there are many famous works of architects such as Vo Trong Nghia, Hoang Thuc Hao, Nguyen Ba Tiep ... The company specializes in design, construction, furniture, handicraft products. Bamboo art is growing and growing. This also shows the potential for future development of bamboo materials.

At present, using the abundant bamboo resources, some enterprises have learned how to apply modern technology to produce high-grade bamboo products such as bamboo flooring, tables, chairs, beds, ceiling panels, wall tiles, furniture. Fine art decoration, interior materials and consumers appreciate the design as well as product quality.

- Add new material sources

The interior materials, paving, wall tiles are made of natural wood, artificial is being used by consumers, can hardly be replaced, the material from the bamboo appear, enrich the market And give customers more choice for their home. Today, with modern technology, bamboo is contributing a lot of new value, being unique material, creative alternative to natural wood and many other artificial materials.

Bamboo products, such as smoked bamboos, blinds from bamboo, bamboo flooring, wall panels, stairs, tables and chairs, cabinets, etc., are being upgraded in terms of design, quality as well as design. Today, bamboo blinds come back with interior decoration but in a new level. The product is produced from old bamboo but has helped with technology machinery so the screen is more beautiful, sharper, sterilized, dried to avoid warping, moldy. Venetian 
blinds are used for resorts and villas that offer luxurious interior spaces that are always close to the natural environment. This decoration is popular in Europe and Japan.

- occupy the wood market

While natural wood is becoming increasingly exhausted, flooring or bamboo furniture offers natural beauty and peace of mind. This product is favored by Western and North American countries as the bamboo has its own technical characteristics such as good elasticity, low warping, high abrasion resistance. Once treated, it can be prevented. Bamboo is $25 \%$ stronger than oak and has high stability with 6 layers of UV and Aluminum Oxide for increased surface hardness, abrasion resistance, European and American quality standards [8]. Industrial products from bamboo are usually classified according to texture and color. Under appropriate conditions, bamboo flooring has a durability of up to 30 years and bamboo furniture is permanently durable. With 2 basic colors: natural and coffee colors, flooring and bamboo furniture suitable for any space. Bring a warm feeling of winter and a cool summer. The bamboo products are derived from the timber industry so that they must comply with the wood industry standards for flooring. For furniture also must adhere to the furniture industry. Bamboo in handicrafts is usually soft bamboo, creating curves. But for bamboo, the need for straight lines produces large panels, which require stiffer bamboo and the treatment process is more durable and long lasting to resist termites, which are resistant to molds to produce a finer product. Solid structure. The technology of turning bamboo into a real new wood and we consider it a revolution in materials because bamboo can be pressed into blocks, large plates up to $2.4 \mathrm{~m}$ long $1.2 \mathrm{~m}$ wide. When pressed like that, it can be used as a substitute for natural wood. As wood is running out, we have this material that works well.

- Towards an export path

At present, the market has gradually become familiar with materials made from bamboo. Currently, the price of bamboo flooring compared with industrial wood, the price of bamboo flooring is more expensive. However, it is inevitable that consumers will be afraid that the product will be expensive and the quality will not be known. The market for bamboo flooring and bamboo furniture is mainly exported to Europe, and to the USA. In particular, in the US market, flooring and furniture products are competing for products from China. Because China has more plentiful raw materials and better technological development, so it is more competitive. Meanwhile, bamboo in Vietnam is stiffer than Chinese bamboo, so in the production process, the type and fiber ratio should be a bit higher. However, in return, the hardness as well as aesthetics of Vietnamese bamboo is completely different and more beautiful than Chinese products. Therefore, bamboo products from Vietnam are still popular among consumers.

Currently in Vietnam, only a few enterprises bravely produce industrial products from this bamboo. However, according to the assessment, this product has the potential and bring big export value for enterprises and can replace the natural wood is exhausted. [17]

- Typical works

Coffee Wind \& Water, Thu Dau Mot - Binh Duong

With the special creativity of architect Vo Trong Nghia and his associates, Wind \& Water Café was awarded the IAA International Architecture Prize 2008. This is a unique architectural work built primarily with the scorpion grows a lot in Binh Duong, making it feel like a huge pile of straw with pretty little entrances [18]. 


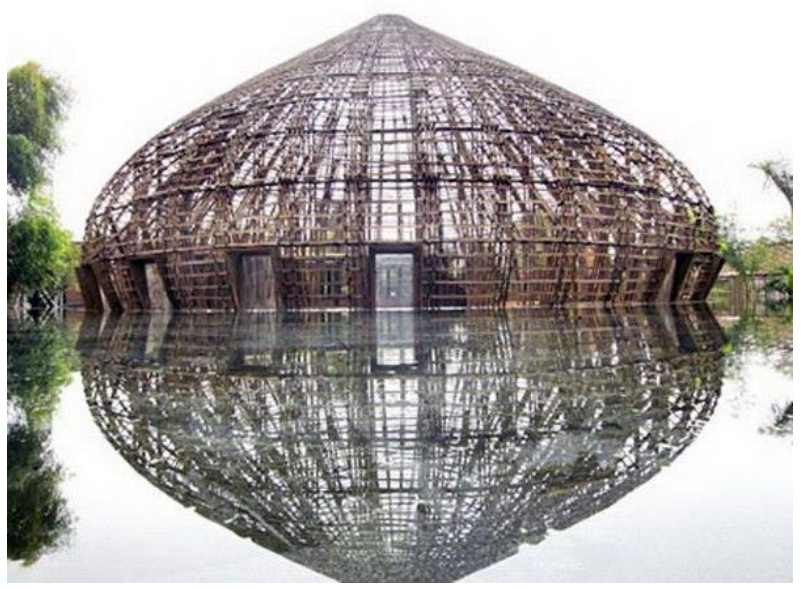

Fig. 9. Works using bamboo texture.

The most special idea of the work is the application of aerodynamic principles. The project uses wind power and cooling capacity of water to form natural air conditioners, saving energy costs.

Between the coffee space floor is a man-made lake. At first glance at the depth of the lake, but actually only the lake is empty. The way to take advantage of the black stone carving on the bottom of the lake has brought a very deep feeling. Where guests sit down to drink coffee than the surface of the lake. According to the explanation of the architect, the layout of such a place to enjoy the cool water flow from the lake to.

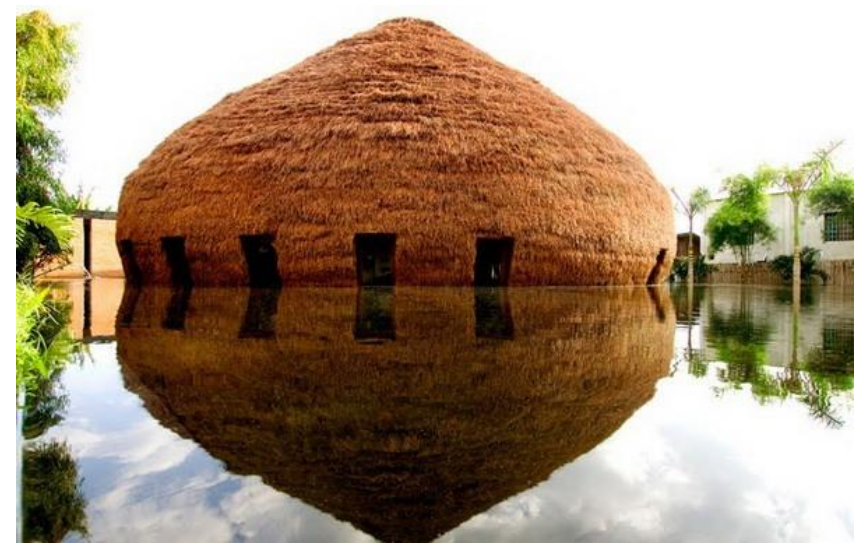

Fig. 10. Works using bamboo texture.

Inside the cafe, where the coffee is located below the water, visitors easily feel the water of the wind. The array of green trees is also interspersed within the shop to create a unique space. [18] 


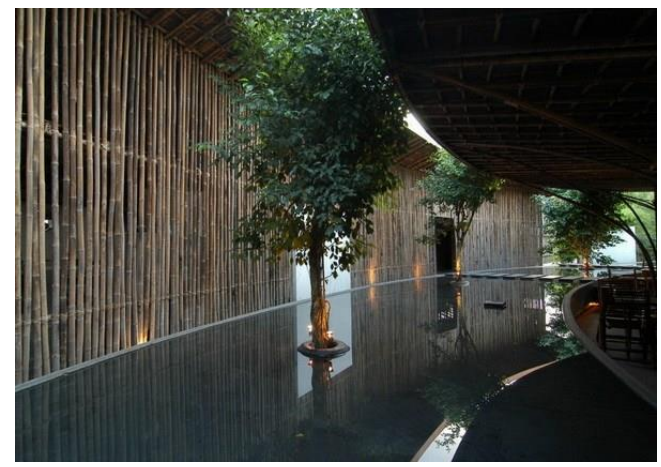

Fig. 10. Works using bamboo texture.

Coming here, visitors just sip a cup of coffee and discover the unique architecture and immerse in the green space with only wind and water. Weekend with a quiet space, melodious music, and cool breezes is a delightful experience.

Bamboo Wing restaurant, Dai Lai - Vinh Phuc.

The Bamboo Wing was invested in architectural ideas from the wings of cranes up from ancient Hung Vuong. Vietnamese quality and environmental friendliness are evident in bamboo framing, at non-metallic links, at the roof of a 'rock' tree, in green hills on service spaces. [18]

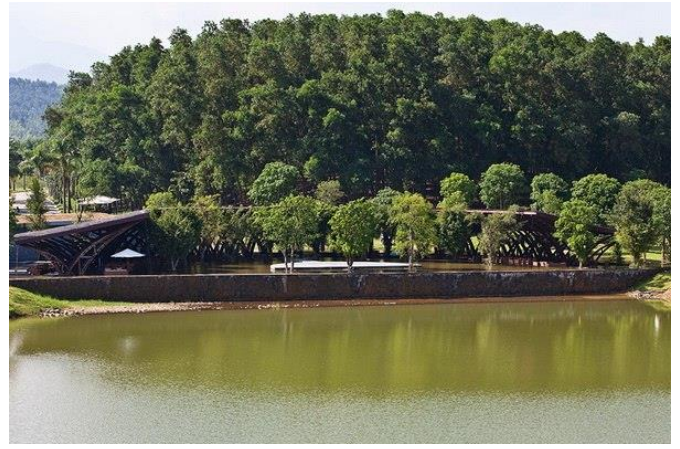

Fig. 11. Works using bamboo texture.

With the highlight of Dai Lai lake, the Bamboo Wing was designed by architect Vo Trong Nghia as two wide wings soaring on the lake, based on the idea from the drum pattern on the surface, while King Hung was building. Just like the two buildings above, the main material of the restaurant is rustic bamboo associated with the homeland, the people of Vietnam.

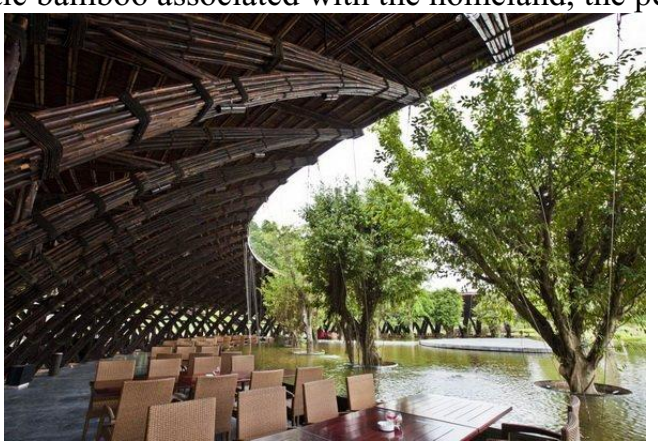

Fig. 12. Works using bamboo texture. 
From a distance, the Bamboo Wing is covered with woods, and the entrance to the boulders is spread over the water. In the daytime, the rays of the sun shining down on Dai Lai Lake like a shimmering crystal glow around the restaurant and the surrounding space. At night, the lamps are cleverly placed in the bamboo tube glowing, creating a warm space and sparkling fanciful, with a completely different experience for visitors here.

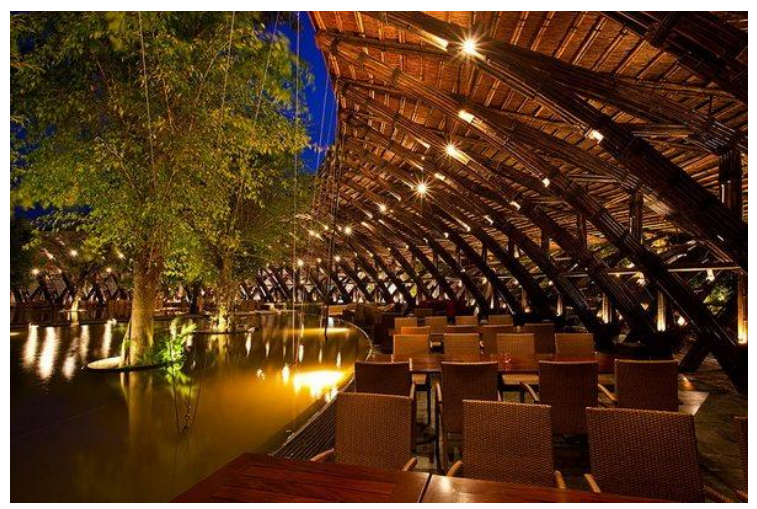

Fig. 13. Works using bamboo texture.

This is the only architecture in Vietnam to be honored along with 89 other international architectural works receiving the International Architecture Award (IAA) - an annual award to honor architectural and architectural works. The best urban plan in the world on 6/7/2011.

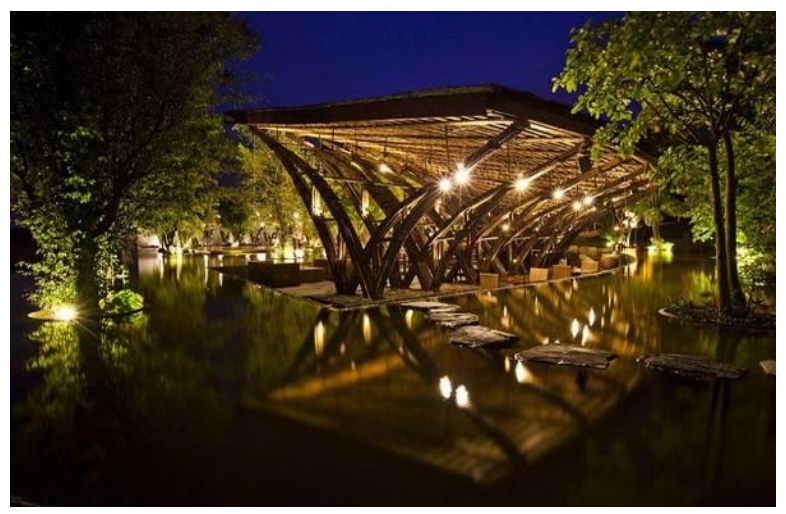

Fig. 14. Works using bamboo texture.

Space fanciful architecture with bold historical value of Bamboo Wing [18].

Recently, Bamboo Wing Restaurant was awarded the Resort and Functional Works of the Year by the Asian Architects Association. [18]

\section{Discussion}

- Always cooperate and develop national and international projects on the application of bamboo in buildings in Vietnam.

- Research themes should be developed to develop specific standards and regulations for the sustainable development of green architecture and architecture in Vietnam.

- Raise awareness and promote the role of contractors, designers, investors in the application of bamboo materials in the design. 
- The government should have a policy to support bamboo farmers, prioritizing the development of ecological projects in rural areas. In addition, the state should also have policies to support companies producing and exporting furniture and handicrafts.

\section{Conclusions}

A collaboration between scientist and designer is important to archive the quality materials, produce good design and has implications not only for the companies but also for consumers and the society. Good design combines the capabilities of a balanced approach in terms of material, commercial design, environment, technology, idealism, and humanitarian concerns will generate benefit product for Life Cycle Assessment without the effect of the ecological system. In other hand, product value can be increased with the use of a material and design that reduces simultaneously the environmental impact and cost effective if manufacturers completely support new material mechanical properties and explore that have the potential to meet the requirements of a new future. Perhaps, the most encouraging trend of all is that we are only beginning to discover how versatile bamboo is as a replacement for hardwoods in all sorts of home building and decorating applications. As we continue to search for ways to lessen our impact on the environment, bamboo may offer us the best chance to save our remaining forests so that future generations can experience the simple joys of a walk in the woods.

Sustainable interior materials have a positive impact on indoor climate and microclimate, thermal comfort, air quality and humidity, in which the quality of the indoor environment is directly related to the health of the occupants. The choice of materials has a huge impact on the environment for interior projects, especially commercial projects, furniture is often replaced after several years of use. While the benefits of sustainable interior design are clear, the fact remains that sustainable or green materials are among the top priorities in choosing interior materials.

Sustainable furniture design is the right direction, the developed countries has been a pioneer in this field as well as theoretical practice. Based on the development of the advanced countries, should have applied practical research consistent with the conditions of Vietnam. VietNam designers are missing a reference tool for the interior design, in order to standardize the criteria for interior design sustainability, such as the assessment tool interior design of sustainable similar system The green building assessment of some countries in the world and in Vietnam is now the Lotus Green Building Rating System [19]. However, this is a long route to start building the tools simple and then edit the practices is the way countries are developing similar to Vietnam has done and has made initial success. Bamboo researchers should share documentation for those investors who play a decisive role in the project interior and really see the benefits of sustainable design for individuals and communities.

Bamboo is favored not only by its natural features and its use but also by the fact that bamboo is a sustainable material. When using bamboo products, we are contributing to the protection of our habitat and our descendants: "Use bamboo instead of wood to retain the blue of the earth for a friendly and sustainable life".

\section{References}

1. P. van der Lugt, Design Interventions for Stimulating Bamboo Commercialization Dutch Design meets Bamboo as a Replicable Model, The Thesis PHD (2008)

2. G. Liu, C. Foster, W. N. French, Introduction to the Tsinghua Bamboo-Strip Manuscripts (Brill, Lam edition, 2016) 
3. M. Kang, D.A. Guerin, The characteristics of interior designers who practice environmentally sustainable interior design (Environ, 2009)

4. R. McMullan, Environmental Science in Building (Hampshire, Basingstoke, 2007)

5. L. Dennis, Fairtrade foundation. What is Fairtrade (2014)

6. J. Kristinsson, Integrated Sustainable Design (Delftdigitalpress, 2012)

7. http://www.bridgestone.com/corporate/news/2012092801.html

8. C. van Uffelen, Bamboo Architecture \& Design (Architecture \& Materials, 2014)

9. T.J. Meredith, Bamboo for Gardens (2009)

10. D. Ayana, A. Gure, Seed Characteristics Of Lowland Bamboo (Oxytenanthera abyssinica, 2014)

11. P.van der Lugt, H. Brezet, Bamboo: a Sustainable Solution for Western Europe Design Cases (2009)

12. Black \& Decker Wood Floors: Hardwood - Laminate - Bamboo - Wood Tile - and More (Cool Springs Press, 2017)

13. M.F. Ashby, Materials and Sustainable Development (2015)

14. Oxford English Dictionary (Oxford University, United Kingdom, 1989)

15. http://www.bambubuild.com/vi/bamboo/

16. http://sangogiare.vn/san-tre

17. http://trelizart.com

18. Vo Trong Nghia, Vo Trong Nghia Architects (Viet Nam, 2015)

19. http://vgbc.org.vn/danh-sach-du-an-lotus

20. R. Proctor, The Sustainable Design Book (2015) 